Published in final edited form as:

Exp Eye Res. 2013 November ; 116: . doi:10.1016/j.exer.2013.10.015.

\title{
Ultrastructural Analysis of the Human Lens Fiber Cell Remodeling Zone and the Initiation of Cellular Compaction
}

\author{
M. Joseph Costello ${ }^{1,{ }^{*}}$, Ashik Mohamed ${ }^{2}$, Kurt O. Gilliland ${ }^{1}$, W. Craig Fowler ${ }^{3}$, and Sönke \\ Johnsen ${ }^{4}$ \\ ${ }^{1}$ Department of Cell Biology and Physiology, University of North Carolina, Chapel Hill, NC \\ ${ }^{2}$ Prof. Brien Holden Eye Research Centre, L V Prasad Eye Institute, Hyderabad, India \\ ${ }^{3}$ Department of Ophthalmology, Univ. of North Carolina, Chapel Hill, NC \\ ${ }^{4}$ Department of Biology, Duke University, Durham, NC
}

\begin{abstract}
The purpose is to determine the nature of the cellular rearrangements occurring through the remodeling zone (RZ) in human donor lenses, identified previously by confocal microscopy to be about $100 \mu \mathrm{m}$ from the capsule. Human donor lenses were fixed with $10 \%$ formalin followed by $4 \%$ paraformaldehyde prior to processing for transmission electron microscopy. Of 27 fixed lenses, ages 22, 55 and 92 years were examined in detail. Overview electron micrographs confirmed the loss of cellular organization present in the outer cortex ( $80 \mu \mathrm{m}$ thick) as the cells transitioned into the RZ. The transition occurred within a few cell layers and fiber cells in the RZ completely lost their classical hexagonal cross-sectional appearance. Cell interfaces became unusually interdigitated and irregular even though the radial cell columns were retained. Gap junctions appeared to be unaffected. After the RZ ( $40 \mu \mathrm{m}$ thick), the cells were still irregular but more recognizable as fiber cells with typical interdigitations and the appearance of undulating membranes. Cell thickness was irregular after the RZ with some cells compacted, while others were not, up to the zone of full compaction in the adult nucleus. Similar dramatic cellular changes were observed within the RZ for each lens regardless of age. Because the cytoskeleton controls cell shape, dramatic cellular rearrangements that occur in the RZ most likely are due to alterations in the associations of crystallins to the lens-specific cytoskeletal beaded intermediate filaments. It is also likely that cytoskeletal attachments to membranes are altered to allow undulating membranes to develop.
\end{abstract}

\section{Keywords}

electron microscopy; fiber cell; compaction; remodeling zone; differentiation

\footnotetext{
(C) 2013 Elsevier Ltd. All rights reserved.

*Corresponding author: M. Joseph Costello, PhD, Department of Cell Biology and Physiology, University of North Carolina School of Medicine, Chapel Hill, NC 27599; mjc@med.unc.edu.

Publisher's Disclaimer: This is a PDF file of an unedited manuscript that has been accepted for publication. As a service to our customers we are providing this early version of the manuscript. The manuscript will undergo copyediting, typesetting, and review of the resulting proof before it is published in its final citable form. Please note that during the production process errors may be discovered which could affect the content, and all legal disclaimers that apply to the journal pertain.
} 


\section{Introduction}

The differentiation of fiber cells in the cortex of human lenses is more complex than previously recognized. In addition to the degradation of membranous organelles to produce an organelle free zone that supports transparency of the lens core (Bassnett, 2009), the differentiating fiber cells undergo dramatic transformations about $100 \mu \mathrm{m}$ from the surface within the remodeling zone (RZ) first described by Lim et al. (2009). This region, only 40 $\mu \mathrm{m}$ wide where nuclei are still found, shows extensive cellular disorganization by laser scanning confocal light microscopy. After immunohistochemical staining of membranes and nuclei, the observed complex cellular rearrangements and membrane undulations suggested the insertion of new membranes and the modification of intercellular junctions within the RZ. They noted that the radial cell columns, which were evident in the outer cortical layers where cells had the classical flattened hexagonal cross-section, were not visible in the RZ. The radial cell columns only appeared again in the deeper layer called the transitional zone (TZ), where cells still had complex irregular shapes without nuclei as they transitioned into the compacted cells of the adult nucleus more than $300 \mu \mathrm{m}$ deeper. An important finding was that the RZ appeared at the same location regardless of the age of the lens over an age range of 16 to 76 years. This implies that all fiber cells in human lens nuclei must have undergone the cellular transformations in the $\mathrm{RZ}$ as part of a highly regulated differentiation process. Because the cells in the RZ appeared condensed and jumbled in confocal images, it was anticipated that this region might act as a barrier to diffusion; however, when an extracellular tracer (Texas red dextran) was applied, it readily diffused through the RZ and the $\mathrm{TZ}$ up to the adult nucleus, which appeared to be the physical barrier about $350 \mu \mathrm{m}$ from the lens surface (Lim et al., 2009).

These remarkable observations about a narrow band within the cortex of adult human lenses invite numerous questions about dramatic changes in cell shape and interactions that can be addressed, in part, with high-resolution thin-section transmission electron microscopy (TEM). Unlike confocal imaging, which has a diffraction limited resolution of about 200 $\mathrm{nm}$, thin sections can be prepared with about $2 \mathrm{~nm}$ resolution to reveal membranes and nuclei directly, as well as protein density and distribution indicated by cytoplasmic texture. Three factors were critical to obtain new structural insights using thin-section TEM. First, a new fixation procedure was employed that preserved whole lenses initially in formalin followed by paraformaldehyde that avoided the shrinkage reported for some formaldehyde fixations (Augusteyn et al., 2008) and that minimized any gradient of fixation. Second, the initial fixation was followed by Vibratome section processing, used extensively to analyze lens nuclear fiber cell membranes and cytoplasmic texture (Costello et al., 2008; Metlapally et al., 2008). Third, montages of thin sections allowed examination of fine details of cellular structure from the capsule, throughout the RZ and into the adult nucleus. This combination provided the excellent preservation and sufficient resolution to describe the initiating events in the formation of the RZ, formation of membrane undulations, changes in the membrane junctions and modifications in cytoplasm staining and texture that result in fiber cell compaction (Al-Ghoul and Costello, 1997; Al-Ghoul et al., 2001; Taylor et al., 1996). We confirmed the presence of the RZ at $100 \mu \mathrm{m}$ from the lens surface over an age range of $22-$ 92 years, similar to the original study, and found that the youngest donor lens at 22 years gave the clearest views of distinct cellular changes within the RZ, which supported the conclusion the cellular integrity was maintained within the RZ and there was no evidence for insertion of new membranes in the RZ.

Beneath the epithelium and elongating fiber cells, the fiber cells in humans have classical flattened hexagonal cross-sections with dimensions about $2 \mu \mathrm{m} \times 10 \mu \mathrm{m}$ and close associations with adjacent fiber cells forming numerous specialized junctions and interdigitations (Kuszak and Costello, 2004). These include ball-and-socket interlocking

Exp Eye Res. Author manuscript; available in PMC 2014 November 01. 
devices (Dickson and Crock, 1972; Dickson and Crock, 1975; Kuszak et al., 1988), edge processes (Taylor et al., 1996), tongue-and-groove interdigitations (Kuwabara, 1975; Taylor et al., 1996; Vrensen et al., 1992), square array junctions (Costello et al., 1985; Costello et al., 1989; Lo and Harding, 1984; Zampighi et al., 1982; Zampighi et al., 1989), and gap junctions (Costello et al., 1992; Goodenough, 1979; Kuszak and Brown, 1994; Lo and Harding, 1986). These specialized structures have important roles in determining cell shape, stabilizing intercellular contacts and minimizing extracellular space, dependent on lens species, lens age and age of the cell within the lens. It is reasonable to expect that gradual modifications of these specialized features transform the outer cortical fiber cells to the highly flattened fiber cells of the human adult nucleus where the interdigitations are more elaborate and the cytoplasm is more condensed, consistent with the higher refractive index of the lens core (Taylor et al., 1996; Jones et al., 2005). However, the presence of the RZ suggests critical stages of fiber cell differentiation might be more dramatic and more rapid than expected. Ball-and-socket interlocking devices are important in this process. Although young fiber cells of the outer cortex in humans and primates have relatively smooth cell surfaces with few ball-and-sockets (Kuszak et al., 1988; Taylor et al., 1996), a pronounced increase in these types of interactions is observed at the beginning of the RZ. Tongue-andgroove specializations are also critical and have been described as characteristic of older fiber cells, especially in the lens center where scanning electron microscopy has shown the undulating membrane topology to cover a major portion of the cell surface (Kuszak et al., 1988; Kuwabara, 1975; Taylor et al., 1996). We show here that formation of undulating membranes is initiated just after the RZ in the mid-cortex and are not present in any membranes within the RZ.

\section{Materials and Methods}

Human donor lenses were obtained from the North Carolina Eye Bank, Winston-Salem, NC and the Ramayamma International Eye Bank, Hyderabad, India, within $24 \mathrm{~h}$ of death. Lenses were collected following the tenets of the Declaration of Helsinki. Whole lenses were immersion fixed in 10\% formalin (neutral buffered containing 1-2\% methanol) for 24 $\mathrm{h}$ followed by fixation in $4 \%$ paraformaldehyde in cacodylate buffer $(\mathrm{pH} 7.2)$ for $48 \mathrm{~h}$ following the protocol described earlier (Costello M.J. et al., Simple Fixation and Storage Protocol for Preserving the Internal Structure of Intact Donor Lenses and Extracted Human Nuclear Cataracts. Invest. Ophthalmol. Vis. Sci. 2012;53:ARVO E-Abstract 3031). Preserved lenses were shipped to University of NC for further processing by TEM using the Vibratome sectioning technique described previously (Costello et al., 2010). Briefly, prefixed lenses were sliced into $200 \mu \mathrm{m}$ thick sections that were immersion fixed $12 \mathrm{~h}$ in $2.5 \%$ glutaraldehyde, $2 \%$ paraformaldehyde and $1 \%$ tannic acid in $0.1 \mathrm{M}$ cacodylate buffer $(\mathrm{pH}$ 7.2) followed by en bloc staining in cold $0.5 \%$ osmium tetroxide for 60 min and $2 \%$ uranyl acetate (in 50\% ethanol) in the dark for $30 \mathrm{~min}$. Thick sections were dehydrated through a graded ethanol series, embedded in epoxy resin (Epon 812, EMS, Hatfield, PA) from which $70 \mathrm{~nm}$ thin sections were cut with a diamond knife (Diatome, EMS, Hatfield, PA). Thin sections were mounted on 300 mesh hexagonal grids and stained with uranyl acetate and lead citrate. Images were obtained using a FEI Tecnai $\mathrm{G}^{2}$ (T12) TEM operated at $80 \mathrm{kV}$ equipped with a Gatan slow scan CCD camera ( $1 \mathrm{k} \times 1 \mathrm{k}$, model 794, Gatan, Pleasanton, CA) and Digital Montage software (Gatan, Pleasanton, CA) for collecting up to $5 \times 7$ arrays of images used to construct extended montages.

\section{Results}

An advantage of the fixation protocol employed is that the short fixation in formalin appears to open access for subsequent fixatives to enter all regions of the lens. After paraformaldehyde fixation, whole lenses were uniformly hard and differences in mechanical 
properties at the capsule/epithelium and cortex/nuclear interfaces seemed to be minimized. The resulting whole fixed lenses were easily Vibratome sectioned and processed for TEM with no obvious distortion of cell shape due to osmotic or mechanical stress as illustrated in images of the equatorial plane showing the capsule, epithelium and elongating fibers from a transparent 22 y.o. donor lens (Fig. 1). Furthermore, the preservation of ultrastructure was excellent, revealed in part by the fine lamella of the capsule, the smooth interface between the capsule and epithelium, the good resolution of the epithelium-fiber cell-interface (Fig. 1, EFI) and the resolution of internal membranous structures. Clearly visible in this image are two nuclei (Fig. 1, N), having well-defined nuclear envelopes, and paired membranes of the irregular interface between adjacent epithelial cells (Fig. 1, arrowheads). In addition, internal organelles can be identified and numerous localized cellular defect vesicles (Fig. 1, black arrows) are visible that most likely represent secondary lysosomes or autophagic vesicles degrading and re-cycling cytoplasmic components (Costello et al., 2013). The mesa yielding these thin sections of epithelium was also used to prepare the subsequent montage of the cortex including the RZ and thus had the same resolution and preservation.

Images from thin sections of the cortex in the equatorial plane near the bow region contain the epithelium (EP) and classical fiber cells (FC) arranged in radial cell columns of flattened hexagonal cells that occasionally display a nucleus (Fig. 2A, cyan line, arrow; Fig. 2B). The thin section extends through the RZ where three regions show changes in cell shape, staining and formation of extensive finger-like interdigitations (Fig. 2A, magenta line; Figs. 2C, D, E). The images in $\mathrm{D}$ and $\mathrm{E}$ show elaborate cellular interactions more complex than any previously described interdigitations, as well as formation of complex cell shapes that obscure the radial cell columns. Just deeper to the RZ, fiber cells in the TZ remain irregular in shape, although radial cell columns can again be detected and cellular compaction begins (Fig. 2A, yellow line; Fig. 2F). Only the initial portion of the TZ is displayed as this region extends about $500 \mu \mathrm{m}$ through the deep cortex to the adult nucleus. Note that within this montage the cytoplasm and membranes change their staining patterns through these outer cortical regions. Thus, classical fiber cells have a light cytoplasm and dark staining membranes whereas fiber cells in the TZ region have dark staining cytoplasm with membranes appearing as white lines. Also note that there are no undulating membranes within the FC and RZ regions. Low amplitude undulations are only barely visible in the initial TZ.

At higher magnification additional ultrastructural details are visible (Fig. 2B-F). The classical fiber cell highlighted is about $2 \mu \mathrm{m}$ thick, relatively uniformly stained and has smooth broad faces (Fig. 2B, cyan). The broad faces are interrupted by a few small circular profiles that represent edge processes, which are small finger-like processes nestled between adjacent fiber cell plasma membranes (Taylor et al., 1996). Note that there are no visible ball-and-socket interdigitations and interlocking devices at the short faces are not elaborate. Flattened hexagonal fiber cells can be recognized throughout the FC region, although in the deeper regions, the cells seem to enlarge, the cytoplasm stains more lightly and the texture is more irregular (Fig. 2A). Dark objects appear in the cytoplasm, which at high magnification are seen to be complex interdigitations between adjacent cells (Fig. 2C, magenta). In the highlighted, cell two such interdigitations are visible with connections intact to adjacent cells reveling their similar topology to ball-and-socket interdigitations (Dickson and Crock, 1972; Zhou and Lo, 2003). However, these structures are distinct in several ways. First, they are larger than typical ball-and-sockets (usually less than $0.5 \mu \mathrm{m}$ ) with some extending more than a micron into adjacent cells and having maximum diameters also more than a micron. Most important is that these complex interdigitations are much more numerous with the highlighted cell having more than ten, compared to the classical fiber cells that had none visible. The dark staining of the objects might in part be due to the internal structure, for example, if the protrusions are generated by extensions of the actin cytoskeleton, the high

Exp Eye Res. Author manuscript; available in PMC 2014 November 01. 
concentration of cytoskeletal proteins may attract additional stain. Furthermore, the lighter staining and more irregular texture of the cytoplasm increases the contrast of the profiles. Once these profiles are recognized as distinct structures, their density can be appreciated at low magnification where hundreds are visible (Fig. 2A). Such objects are easily distinguished from membranous organelles, such as the secondary lysosome or autophagic vesicle containing membranes and heterogeneous contents (Fig. 2C, arrow). In this region the cells are also beginning to lose their classical shape.

In the middle of the RZ, the cells are so irregular in shape that they, by themselves, would not be recognizable as being from any mammalian lens (Fig. 2D, magenta highlighted cell). The interdigitations are extensive and irregular in size and distribution, which distorts the shapes and appearance of the fiber cells. Note that some of the projections are darkly stained and others are light, suggesting that proteins that take up stain are being redistributed. The cytoplasmic texture of the highlighted cell also appears to be more uniform than the adjacent cells or cells from the previous region of the RZ (compare Fig. 2D and 2C). These distinctions can be appreciated at low magnification as well (Fig. 2A). The dramatic change in the texture of the cytoplasm is even more pronounced in the deepest region of the RZ where all the cells have smooth uniform cytoplasmic texture (Fig. 2E). The highlighted cell has numerous projections of irregular size, shape and staining density, and the overall shape of the cell is very irregular (Fig. 2E, magenta cell). The cell to the immediate left has few projections in the cytoplasm whereas the one to the right has more than $70 \%$ of the exposed region filled with projection profiles (Fig. 2E). These features suggest that there are massive rearrangements of both membrane components and cytoplasmic proteins.

Just deep to the RZ, the TZ begins to display characteristics of fiber cells of the human lens nucleus with cytoplasm that is both uniformly stained and uniform in texture (Taylor et al., 1996). The cell shape, while still irregular, can be found within radial cell columns and interdigitations may be simpler. For example, the highlighted cell has one projection from an adjacent cell with a narrow opening and wide tip; the eight other circular profiles might be sections through tips of other projections, and if so, would suggest that none of the profiles have been pinched off to form objects entirely contained within the cytoplasm. We have offered this interpretation previously to account for the complex morphology of nuclear fiber cells (Taylor et al., 1996). Although this complex pattern of membranes would have to be confirmed in 3D tomographic reconstructions, these images support the interpretation that membrane bound objects within the plasma membrane perimeter are projections from adjacent cells.

Such an interpretation of the pattern of membranes in mature fiber cells requires that the intercellular projections have double membranes, one plasma membrane from each cell. The ultrastructure confirms this pattern of membranes as illustrated at high magnification (Fig. 3, an enlargement of the boxed region in Fig. 2C). In this image each plasma membrane is seen as a thin dark line (Fig. 3, arrowheads). The interface between adjacent cells is formed by two plasma membranes, which can be followed into two projections where the neck is within the thin section. Most of the projections are clearly covered by paired plasma membranes and are most likely sections through the broad tips of projections where the necks are out of the plane of the thin section. A typical gap junction of closely apposed membranes is marked (Fig. 3, arrow). The amount of plasma membrane visible in this image suggests that the fiber cells are intact; that is, there is no morphological evidence for fiber cell breakdown or disruption within the RZ. Furthermore, gap junctions appear to be preserved, and, if functional, would promote intercellular communication and coordination of cellular rearrangements within the RZ. 
At a depth of less than $50 \mu \mathrm{m}$ beyond the end of the montage in Fig. 2, the fiber cells are representative of the deep cortex (Fig. 4A). The cytoplasm is dense and uniform and the cell interfaces begin to display the undulating membranes characteristic of tongue-and-groove interdigitations, which can be low amplitude (Fig. 4A, arrowheads) or high amplitude (Fig. $4 \mathrm{~A}$, arrows). In both cases the paired membranes and the extracellular space are contained within the white lines that are prominent in thin section images of mature fiber cells. At any given location the visibility of the membranes is limited mainly due to the complex geometry of the membranes and low probability that the membrane will be viewed edge-on (Costello et al., 1992; Costello et al., 2008). With careful selection, regions can be found where membranes have the proper orientation perpendicular to the plane of the thin section (Fig. 4B). For this region of high amplitude undulations, the membrane components most likely have been separated into domains where aquaporin 0 orthogonal arrays appear on the convex segments (Fig. 4B, arrowheads) and protein poor lipid bilayers occupy the concave segments (Fig. 4B, arrows) based on previous studies (Costello et al., 1985; 2008; Kuszak and Brown, 1994; Lo and Harding, 1984; Zampighi et al., 1989). The important consideration here is that the undulations do not occur unless the membrane proteins and lipids have been reorganized. Thus the first appearance of the undulations in the beginning of the TZ (Fig. 2A, 2F) suggests that this region identifies the origin of the undulations along the path of human fiber cell differentiation and maturation. The cellular changes described for the 22 y.o. donor lens were observed for all lenses regardless of age and appear to represent a general component of fiber cell differentiation.

At the cortex/nucleus interface about $750 \mu \mathrm{m}$ from the surface, the fiber cells display extensive compaction (Taylor et al., 1996). Unlike the cellular changes within the RZ, which were similar over an extended age range, the amount of cellular compaction observed is strongly dependent on the age of the lens (Fig. 5). For the youngest lens examined at 22 y.o., the amount of compaction was relatively slight with the average cell-to-cell spacing in radial cell columns of compacted cells of about $1 \mu \mathrm{m}$ (Fig. 5A). At age 55 years, the compaction was greater yielding cell spacing of about $0.6-0.8 \mu \mathrm{m}$ (Fig. 5B). The greatest amount of compaction was observed in the 92 year old with a cell spacing of about $0.4-0.6 \mu \mathrm{m}$ (Fig. 5C). This lens also showed more localized sites of cellular disruption (Fig. 5C, arrow) that might contribute to increased retinal stray light or the beginning of cortical cataracts. The extent of compaction in the adult nucleus is expected to be dependent on the number of years of cell growth beyond puberty, which is less than 10 years for the youngest age and over 70 years for the oldest.

\section{Discussion}

The zone of cellular remodeling during fiber cell differentiation in the human transparent lens is a narrow band in the outer cortex that involves dramatic changes in cell shape, interdigitations, cytoplasmic protein packing and, most likely, cytoskeletal patterns. The modification of fiber cells begins within a few cell layers about $80 \mu \mathrm{m}$ from the capsule with the formation of complex interdigitations as extensive finger-like projections similar in topography to ball-and-socket interlocking devices except much more numerous.

Thus, the interface between cells appears to change dramatically without loss of cell integrity or gap junctions. The projections initially are recognized as distinct objects because they stain more darkly than the adjacent cytoplasm, which at the same time appears to be more textured and lighter staining than the neighboring classical fiber cells (Fig. 2A). The large number of projections and the contrasting staining density with the adjacent cytoplasm has not been reported previously and were not visible in the confocal images of the original description of the RZ (Lim et al., 2009). In the middle of the RZ, the cytoplasmic proteins appear to be redistributed gradually to produce a more uniform texture and density more 
similar to the cytoplasm within the projections (compare Fig. 2C to 2D). These changes suggest that redistributions occur both of soluble crystallins, which constitute the major mass within fiber cells, and of cytoskeletal proteins that control cell shape.

Actin is an important component of the cytoskeleton during cell elongation and might partially account for the intense staining of the elongating fibers at the EFI (Fig. 1) (Bassnett et al., 1999; Beebe et al., 2001; Lo et al., 1997; Rafferty and Goossens, 1978). Importantly, actin has been associated with ball-and-socket formation as intercellular projections of varying size and location depending on species and cell age (Biswas et al., 2010; Dickson and Crock, 1972; Zhou and Lo, 2003). Labeling studies have clearly shown actin within the protrusions in primate lenses, and branching actin filaments were visualized by TEM (Zhou and Lo, 2003). Therefore, it is reasonable to hypothesize that the extensive and rapidly formed protrusions into adjacent cells in the RZ are produced by stimulation of the actin cytoskeleton, although this hypothesis will have to be confirmed in future studies with high resolution specific labeling.

It is likely that the beaded filament cytoskeleton formed by filensin and phakinin influences cortical fiber cell shape (FitzGerald, 2009) and is modified in the formation of the RZ. However, beaded filaments and other cytoskeletal elements are not normally visible in thin sections of intact fiber cells and have only been visualized after the soluble crystallins have been removed leaving a cytoplasmic ghost (Alizadeh et al., 2004; Schietroma et al., 2009). It is well established that the beaded filament proteins are degraded with age, which may be caused by endogenous enzymes (Sandilands et al., 1995; Blankenship et al., 2001;

FitzGerald, 2009). It has been suggested that modification of the beaded filament arrays and other cytoskeletal components may be caused by calpain 2, a calcium dependent cysteine protease identified in many species including human (David et al., 1989). Calpain may also remodel the membrane skeleton, which includes many actin-binding proteins (Beebe et al., 2001; Gokhin et al., 2012; Lee et al., 2000; Maddala et al., 2011). In a mouse model it was demonstrated that calpain cleaved spectrin with greatest enzyme activity in a $100 \mu \mathrm{m}$ thick band in the outer cortex adjacent to the organelle free zone (De Maria et al., 2009). Disruption of the spectin binding to actin and membrane components might be one factor underlying the dramatic remodeling of the plasma membrane that occurs during fiber cell maturation to produce the interlocking folds and undulations (De Maria et al., 2009). Another factor may be the remodeling of the beaded filaments and the reported direct links of beaded filament proteins to aquaporin0 membrane proteins (Lindsey Rose et al., 2006). In a phakinin (CP49) knock out mouse model, it was recently shown that the absence of beaded filaments resulted in an large increase in undulating membranes (Biswas et al., The Tropomodulin1-Actin Network and CP49 Beaded Filaments Regulate Formation of Undulating Aquaporin Junctions in Mouse Lens Fiber Cells. Invest Ophthalmol Vis Sci 2013;54: E-Abstract 5734). The ultrastructural data presented here for humans are consistent with these results for mouse models because none of the membrane interfaces from the epithelium through the RZ show membrane undulations, whereas all cells in the TZ and deeper layers are characterized by the undulations. Therefore, for the first time we have identified the origin of fiber cell membrane undulations in the beginning of the TZ within the mid-cortex.

The proposed enzymatic modifications of the cytoskeleton and membrane skeleton may help explain the distinctive pattern of staining in thin sections. The stains used are mainly positively charged heavy metal ions, such as uranium and lead, which will bind to negatively charged regions on the surfaces of proteins. It is possible that crystallins bind to each other and to beaded filaments at the negatively charged regions, such that the binding sites would initially compete with the heavy metal ions, resulting in a lower overall staining in the FC and early RZ. After the remodeling of the cytoskeleton and modifications to 
crystallins (Grey and Schey, 2009), the crystallins could reorganize exposing heavy metal binding sites to form the densely stained cytoplasm in deep cortical cells in the TZ. In contrast, the membrane skeleton is robust in the young classical fiber cells (Fig. 2A, FC), which may absorb stains to enhance the membranes against a lighter staining cytoplasm. After the proposed modifications of the membrane skeleton in the RZ, the membrane bilayer will still have its distinctive bilayer staining pattern, only the overall membrane staining will be much lighter compared to the dense matrix of cytoplasmic crystallins. Thus, these results provide an explanation why the membranes are seen in negative contrast as white lines at low magnification in the TZ.

The most important observation about the unusual patterns of staining, which have not been described previously, is the transition in cytoplasmic staining from the classical fiber cells to the beginning of the RZ (Fig. 2A, FC to RZ) where the cells enlarge, the cytoplasm becomes more textured and is more electron translucent. These modifications in staining are remarkable for several reasons. First, the unusually high level of preservation of cellular detail suggests that the staining patterns, as well as accompanying changes in cell shape, are consistent with modifications of both cytoplasmic proteins and cytoskeleton. Second, there have been no previous ultrastructural reports of well-preserved fiber cells throughout the cortex. Third, the variations in texture of the cytoplasm are carefully recorded using the Vibratome sectioning method of processing (Metlapally et al., 2008) suggesting that the observed smooth condensed cytoplasm in the TZ is a result of significant modifications of the packing of cytoplasmic crystallins. How is it possible that these unusual patterns of stain and dramatic changes in cell shape could have been missed in previous morphological studies? For nearly forty years prior to the initial description of the RZ in 2009 (Lim et al., 2009), normal and cataractous human lenses have been examined by ultrastructural methods without any mention in the literature of fiber cells with properties displayed in the RZ or any images that accidently display these distinctive cells. Lim et al. (Lim et al., 2009) offer the explanation that the main emphasis has been in the human lens nucleus and nuclear cataract formation, often using extracted nuclei where the cortex had been removed. Moreover, special emphasis is often given to the initial stages of fiber cell elongation and early differentiation. Another factor is that the RZ may be difficult to preserve with conventional fixation procedures. It is likely that the initial exposure to formalin is very gentle, perhaps through the infusion of small molecules including methanol, which can penetrate barriers without creating osmotic gradients. If fixation is not sufficient, then disruption or disorganization of cells may occur and these regions might have been avoided in previous studies.

Another issue that can be addressed in this study concerns the possible function of the RZ in human lenses. Based on the unique pattern of cell compaction in human adult nuclei (AlGhoul and Costello, 1997; Taylor et al., 1996), we suggest that the changes in the RZ are required to prepare the fiber cells for their compaction in the adult nucleus from about $2 \mu \mathrm{m}$ to $0.5 \mu \mathrm{m}$ per cell. Compaction occurs while radial cell columns are preserved, broad faces of adjacent fiber cells become extensively interdigitated, membrane topology becomes dominated with undulations and the cytoplasm becomes very dense and uniform. None of these properties could be achieved without the cell modifications described in the RZ, which occurs for all fiber cells regardless of age. Thus our observations that the same cellular changes occurred in each lens examined over the age range of 22-92 years are consistent with the presence of the $\mathrm{RZ}$ at the same location in the original publication over the range 16-76 years (Lim et al., 2009). The amount of compaction we observed, however, is strongly dependent on age with the young lens showing little compaction in the adult nucleus and the oldest lens showing the most compaction near $0.5 \mu \mathrm{m}$ per cell average thickness. Also many more focal sites of cell disruption, compared to the younger lenses, were observed in the 92 y.o. lens (Fig. 5C, arrow), suggesting that age and cumulative 
exposure to light and other possible oxidative stresses caused cell damage that contributes to age-related scattering as retinal stray light (Vrensen 2009). These possible sources of light scattering are distinct from those observed within the RZ. The numerous projections in the RZ that have different density from the adjacent cytoplasm can be modeled as nearly spherical objects (with circular cross-sections) about 0.5-1.0 $\mu \mathrm{m}$ average diameter and a density greater than 100,000 per $\mathrm{mm}^{3}$. Mie scattering theory suggests that the RZ, as annular band, would scatter a significant amount of light and also contribute to the retinal stray light. However, because the band is so thin at less than $40 \mu \mathrm{m}$, the effect on image formation at the retina for light passing close to the optic axis (nearly perpendicular to the RZ) would be minimal. As noted by Lim et al. (Lim et al., 2009), the band could be distinctive with oblique illumination and could account for the zone of discontinuity in slit lamp images about $100 \mu \mathrm{m}$ from the capsule (Michael and Bron, 2011). Thus, our preliminary examination of the cellular properties of the RZ agrees with the conclusion of increased scattering in the RZ reached by Lim et al. (Lim et al., 2009) for different reasons: they proposed that the scattering was due to cell disorganization whereas our results suggest that the initial interdigitation pattern produced numerous unique scattering centers without cell disruption.

\section{Conclusions}

Fiber cells in the RZ undergo extensive changes in cell shape by forming complex interdigitations with adjacent cells without apparently compromising cell integrity or gap junctional interactions. Changes to fiber cells suggest extensive redistribution of the cytoskeleton and remodeling of the associations between the cytoskeleton and membranes. Alterations of crystallin-cytoskeleton interactions support the condensation of crystallins and darker cytoplasmic staining observed in the deep cortex and nucleus.

\section{Acknowledgments}

We wish to thank Mr. Hal Mekeel for expert technical assistance with sample preparation and electron microscopy. This work was supported in part by NIH grants EY008148 (MJC) and EY005722 (Duke Eye Center Core Grant).

\section{References}

Al-Ghoul KJ, Costello MJ. Light microscopic variation of fiber cell size, shape and ordering in the equatorial plane of bovine and human lenses. Mol Vis. 1997; 3:2. [PubMed: 9238091]

Al-Ghoul KJ, Nordgren RK, Kuszak AJ, Freel CD, Costello MJ, Kuszak JR. Structural evidence of human nuclear fiber compaction as a function of ageing and cataractogenesis. Exp Eye Res. 2001; 72:199-214. [PubMed: 11180969]

Alizadeh A, Clark J, Seeberger T, Hess J, Blankenship T, FitzGerald PG. Characterization of a mutation in the lens-specific CP49 in the 129 strain of mouse. Invest Ophthalmol Vis Sci. 2004; 45:884-891. [PubMed: 14985306]

Bassnett S. On the mechanism of organelle degradation in the vertebrate lens. Exp Eye Res. 2009; 88:133-139. [PubMed: 18840431]

Bassnett S, Missey H, Vucemilo I. Molecular architecture of the lens fiber cell basal membrane complex. J Cell Sci. 1999; 112(Pt 13):2155-2165. [PubMed: 10362545]

Beebe DC, Vasiliev O, Guo J, Shui YB, Bassnett S. Changes in adhesion complexes define stages in the differentiation of lens fiber cells. Invest Ophthalmol Vis Sci. 2001; 42:727-734. [PubMed: 11222534]

Biswas SK, Lee JE, Brako L, Jiang JX, Lo WK. Gap junctions are selectively associated with interlocking ball-and-sockets but not protrusions in the lens. Mol Vis. 2010; 16:2328-2341. [PubMed: 21139982] 
Blankenship TN, Hess JF, FitzGerald PG. Development-and differentiation-dependent reorganization of intermediate filaments in fiber cells. Invest Ophthalmol Vis Sci. 2001 Mar; 42(3):735-742. [PubMed: 11222535]

Costello MJ, Johnsen S, Metlapally S, Gilliland KO, Frame L, Balasubramanian D. Multilamellar spherical particles as potential sources of excessive light scattering in human age-related nuclear cataracts. Exp Eye Res. 2010; 91:881-889. [PubMed: 20888812]

Costello MJ, Johnsen S, Metlapally S, Gilliland KO, Ramamurthy B, Krishna PV, Balasubramanian D. Ultrastructural analysis of damage to nuclear fiber cell membranes in advanced age-related cataracts from India. Exp Eye Res. 2008; 87:147-158. [PubMed: 18617164]

Costello MJ, McIntosh TJ, Robertson JD. Membrane specializations in mammalian lens fiber cells: distribution of square arrays. Curr Eye Res. 1985; 4:1183-1201. [PubMed: 4075818]

Costello MJ, McIntosh TJ, Robertson JD. Distribution of gap junctions and square array junctions in the mammalian lens. Invest Ophthalmol Vis Sci. 1989; 30:975-989. [PubMed: 2722452]

Costello MJ, Oliver TN, Cobo LM. Cellular architecture in age-related human nuclear cataracts. Invest Ophthalmol Vis Sci. 1992; 33:3209-3227. [PubMed: 1399426]

Costello MJ, Brennan LA, Basu S, Chauss D, Mohamed A, Gilliland KO, Johnsen S, Menko S, Kantorow M. Autophagy and mitophagy participate in ocular lens organelle degradation. Exp Eye Res. 2013 PMID: 24012988.

David LL, Varnum MD, Lampi KJ, Shearer TR. Calpain II in human lens. Invest Ophthalmol Vis Sci. 1989; 30:269-275. [PubMed: 2536646]

De Maria A, Shi Y, Kumar NM, Bassnett S. Calpain expression and activity during lens fiber cell differentiation. J Biol Chem. 2009; 284:13542-13550. [PubMed: 19269960]

Dickson DH, Crock GW. Interlocking patterns on primate lens fibers. Invest Ophthalmol. 1972; 11:809-815. [PubMed: 4627255]

Dickson, DH.; Crock, GW. Fine structure of primate lens fibers. In: Bellows, JG., editor. Cataract and Abnormalities of the Lens. New York: Grune \& Stratton; 1975. p. 49-58.

FitzGerald PG. Lens intermediate filaments. Exp Eye Res. 2009; 88:165-172. [PubMed: 19071112]

Gokhin DS, Nowak RB, Kim NE, Arnett EE, Chen AC, Sah RL, Clark JI, Fowler VM. Tmod1 and CP49 synergize to control the fiber cell geometry, transparency, and mechanical stiffness of the mouse lens. PLoS One. 2012; 7:e48734. [PubMed: 23144950]

Goodenough DA. Lens gap junctions: a structural hypothesis for nonregulated low-resistance intercellular pathways. Invest Ophthalmol Vis Sci. 1979; 18:1104-1122. [PubMed: 511455]

Grey AC, Schey KL. Age-related changes in the spatial distribution of human lens alpha-crystallin products by MALDI imaging mass spectrometry. Invest Ophthalmol Vis Sci. 2009; 50:4319-4329. [PubMed: 19387068]

Guilluy C, Garcia-Mata R, Burridge K. Rho protein crosstalk: another social network? Trends Cell Biol. 2011; 21:718-726. [PubMed: 21924908]

Jones CE, Atchison DA, Meder R, Pope JM. Refractive index distribution and optical properties of the isolated human lens measured using magnetic resonance imaging (MRI). Vision Res. 2005; 45:2352-2366. [PubMed: 15979462]

Kuszak, JR.; Brown, HG. Embryology and anatomy of the lens. In: Albert, DM.; Jakobiec, FA., editors. Principles and Practice of Ophthalmology. Philadelphia: W. B. Saunders; 1994. p. 82-96.

Kuszak, JR.; Costello, MJ. Structure of the Vertebrate Lens. In: Lovicu, FJ.; Robinson, ML., editors. Development of the Ocular Lens. Wiley and Sons Inc; 2004. p. 71-118.

Kuszak JR, Ennesser CA, Umlas J, Macsai-Kaplan MS, Weinstein RS. The ultrastructure of fiber cells in primate lenses: a model for studying membrane senescence. J Ultrastruct Mol Struct Res. 1988; 100:60-74. [PubMed: 3209860]

Kuwabara T. The maturation of the lens cell: a morphologic study. Exp Eye Res. 1975; 20:427-443. [PubMed: 1126408]

Lee A, Fischer RS, Fowler VM. Stabilization and remodeling of the membrane skeleton during lens fiber cell differentiation and maturation. Dev Dyn. 2000; 217:257-270. [PubMed: 10741420]

Exp Eye Res. Author manuscript; available in PMC 2014 November 01. 
Lim JC, Walker KL, Sherwin T, Schey KL, Donaldson PJ. Confocal microscopy reveals zones of membrane remodeling in the outer cortex of the human lens. Invest Ophthalmol Vis Sci. 2009; 50:4304-4310. [PubMed: 19357350]

Lindsey Rose KM, Gourdie RG, Prescott AR, Quinlan RA, Crouch RK, Schey KL. The C terminus of lens aquaporin 0 interacts with the cytoskeletal proteins filensin and CP49. Invest Ophthalmol Vis Sci. 2006; 47:1562-1570. [PubMed: 16565393]

Lo WK. Adherens junctions in the ocular lens of various species: ultrastructural analysis with an improved fixation. Cell Tissue Res. 1988; 254:31-40. [PubMed: 3143480]

Lo WK, Harding CV. Square arrays and their role in ridge formation in human lens fibers. J Ultrastruct Res. 1984; 86:228-245. [PubMed: 6544861]

Lo WK, Harding CV. Structure and distribution of gap junctions in lens epithelium and fiber cells. Cell Tissue Res. 1986; 244:253-263. [PubMed: 3487382]

Lo WK, Shaw AP, Wen XJ. Actin filament bundles in cortical fiber cells of the rat lens. Exp Eye Res. 1997; 65:691-701. [PubMed: 9367649]

Maddala R, Skiba NP, Lalane R 3rd, Sherman DL, Brophy PJ, Rao PV. Periaxin is required for hexagonal geometry and membrane organization of mature lens fibers. Dev Biol. 2011; 357:179_ 190. [PubMed: 21745462]

Metlapally S, Costello MJ, Gilliland KO, Ramamurthy B, Krishna PV, Balasubramanian D, Johnsen S. Analysis of nuclear fiber cell cytoplasmic texture in advanced cataractous lenses from Indian subjects using Debye-Bueche theory. Exp Eye Res. 2008; 86:434-444. [PubMed: 18191834]

Michael R, Bron AJ. The ageing lens and cataract: a model of normal and pathological ageing. Philos Trans R Soc Lond B Biol Sci. 2011; 366:1278-1292. [PubMed: 21402586]

Rafferty NS, Goossens W. Cytoplasmic filaments in the crystalline lens of various species: functional correlations. Exp Eye Res. 1978; 26:177-190. [PubMed: 305361]

Sandilands A, Prescott AR, Hutcheson AM, Quinlan RA, Casselman JT, FitzGerald PG. Filensin is proteolytically processed during lens fiber cell differentiation by multiple independent pathways. Eur J Cell Biol. 1995 Jul; 67(3):238-253. [PubMed: 7588880]

Schietroma C, Fain N, Zampighi LM, Lanzavecchia S, Zampighi GA. The structure of the cytoplasm of lens fibers as determined by conical tomography. Exp Eye Res. 2009; 88:566-574. [PubMed: 19103200]

Taylor VL, al-Ghoul KJ, Lane CW, Davis VA, Kuszak JR, Costello MJ. Morphology of the normal human lens. Invest Ophthalmol Vis Sci. 1996; 37:1396-1410. [PubMed: 8641842]

Vrensen G, Van Marle J, Van Veen H, Willekens B. Membrane architecture as a function of lens fibre maturation: a freeze fracture and scanning electron microscopic study in the human lens. Exp Eye Res. 1992; 54:433-446. [PubMed: 1521571]

Vrensen GF. Early cortical lens opacities: a short overview. Acta Ophthalmol. 2009; 87:602-610. [PubMed: 19719805]

Zampighi G, Simon SA, Robertson JD, McIntosh TJ, Costello MJ. On the structural organization of isolated bovine lens fiber junctions. J Cell Biol. 1982; 93:175-189. [PubMed: 7068755]

Zampighi GA, Hall JE, Ehring GR, Simon SA. The structural organization and protein composition of lens fiber junctions. J Cell Biol. 1989; 108:2255-2275. [PubMed: 2738093]

Zhou CJ, Lo WK. Association of clathrin, AP-2 adaptor and actin cytoskeleton with developing interlocking membrane domains of lens fibre cells. Exp Eye Res. 2003; 77:423-432. [PubMed: 12957142]

Exp Eye Res. Author manuscript; available in PMC 2014 November 01. 


\section{Research Highlights}

Fiber cell shape changes in remodeling zone explained Insights into human fiber cell differentiation obtained

Origin of undulating membranes and compaction shown

Exp Eye Res. Author manuscript; available in PMC 2014 November 01. 


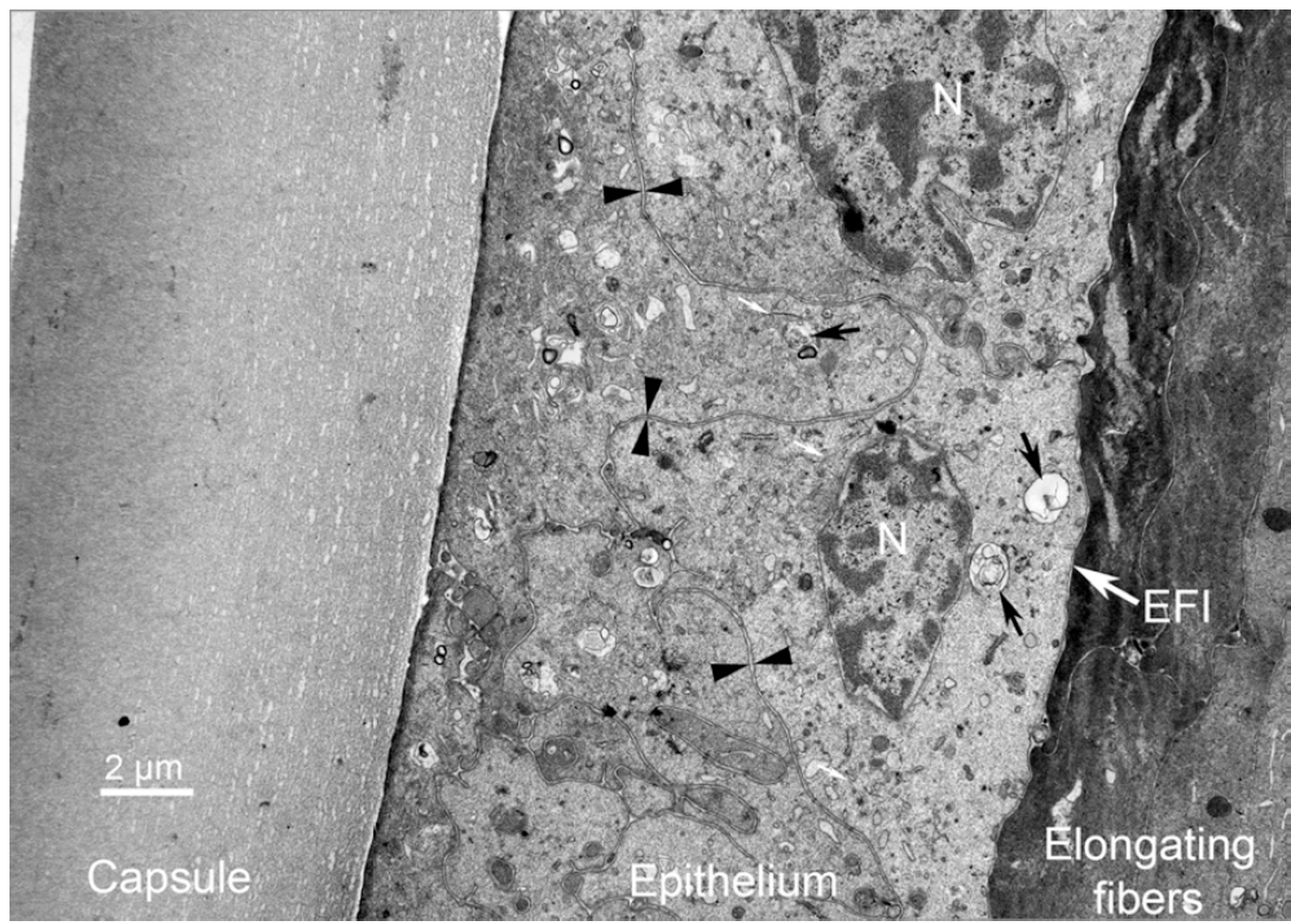

Figure 1. Thin section TEM image of intact human lens capsule and epithelium

The full width of the capsule is visible at the top of the image (10 $\mu \mathrm{m}$ thick) in this section from near the equatorial plane. The fine layering of the non-fibrous basement membrane of the capsule is visible near the epithelium. The epithelium shows portions of several cells separated by paired plasma membranes (arrowheads). Two nuclei $(\mathrm{N})$ are present with clearly defined inner nuclear membranes. Internal membranous organelles, such as endoplasmic reticulum and mitochondria, are visible as are numerous vesicles containing partially degraded cellular material (black arrows). These vesicles are most likely secondary lysosomes or autophagic vesicles. Microfilaments are labeled at three locations (small white arrows). The epithelial-fiber cell-interface (EFI) is distinct because of the high staining density of the elongating fiber cells. (22 y.o. Indian donor). 

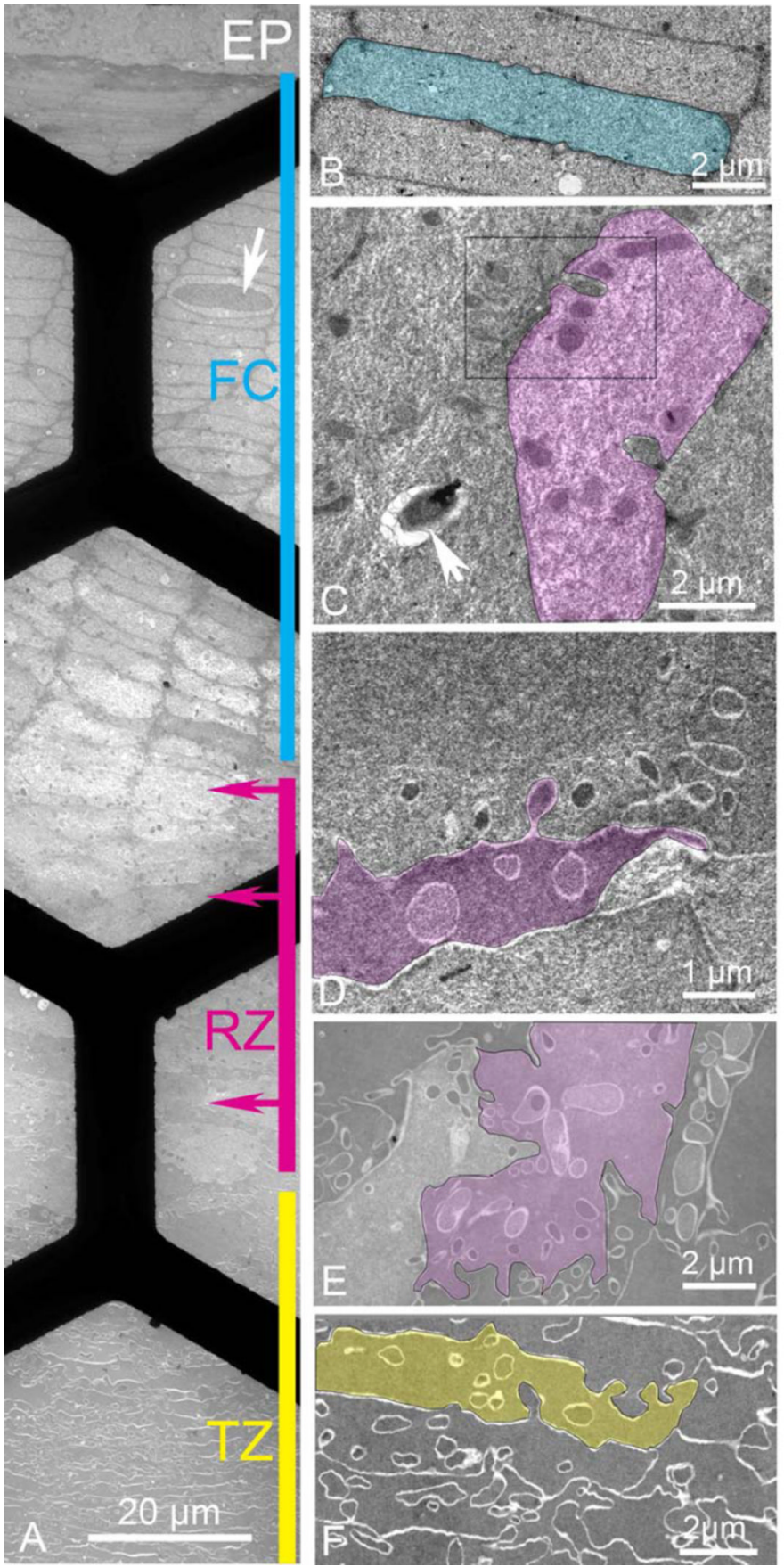

Figure 2. Thin section TEM montage from the epithelium to a depth of about $150 \mu \mathrm{m}$ recorded in the equatorial plane from an adjacent region in the same sample as in Fig. 1

A Overview montage showing four distinct regions: epithelium (EP), classical fiber cells (FC; cyan, $80 \mu \mathrm{m}$ thick), remodeling zone (RZ; magenta, $40 \mu \mathrm{m}$ thick), and transitional zone (TZ; yellow, $>500 \mu \mathrm{m}$ thick). Many cells in FC contain nuclei even though only one is shown (arrow). Arrows on the magenta bar represent the depth from the epithelium where enlargements are made. Black bars are visible from the 300 mesh hexagonal support grid. B. Higher magnification of a classical fiber cell indicates the $2 \mu \mathrm{m} \times 10 \mu \mathrm{m}$ flattened hexagonal shape with smooth broad faces interrupted by only a few small edge processes (small circular profiles). C. Beginning of RZ (upper magenta arrow in A) reveals numerous 
intercellular projections that look like ball-and-socket interlocking devices (two remain connected in the highlighted cell). The bulbous ends stain darkly against a light and textured cytoplasm. The boxed region is enlarged in Fig. 3. A vesicle containing heterogeneous debris is probably a secondary lysosome (arrow). D. The middle of the RZ (middle magenta arrow in A) is characterized by cells of irregular shape with many interdigitating processes of varying size and staining density (highlighted cell). E. Deep in the RZ (lower magenta arrow in A) cells are still very irregular in shape and internal projections are variable. In some cells projections are nearly $2 \mu \mathrm{m}$ in diameter and irregular in outline with smooth interiors similar to the adjacent cytoplasm (highlighted cell). The narrow cell to the right has the majority of the cytoplasm filled with projections whereas other cells have very few. F. Beginning of the TZ has cells, which are more uniform in staining density and texture with fewer projections. Although the cell shape is still irregular, radial cell columns can be identified and early stages of compaction and undulating membranes can be recognized (highlighted cell). 


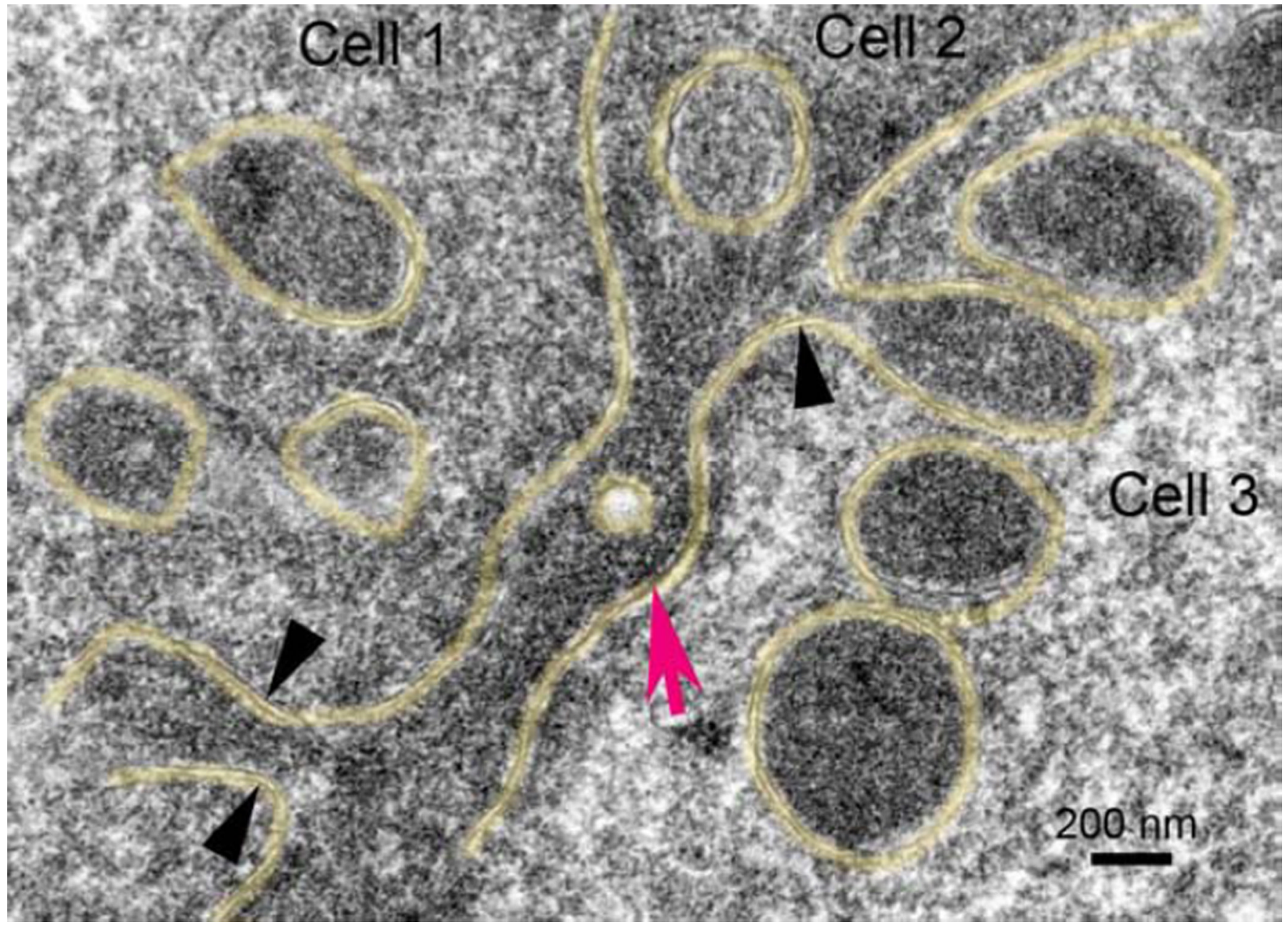

Figure 3. High magnification TEM image of early cellular changes in the RZ

Enlargement of the boxed region in Fig. 2C.Complex interdigitations of three adjacent cells. Two processes have the base connected whereas portions of at least seven others have their connections out of the plane of the thin section. Paired plasma membranes are present throughout. Single plasma membranes are thin dark lines (arrowheads) and one gap junction is marked (arrow). Yellow highlighting is used to increase contrast at cellular interfaces. 

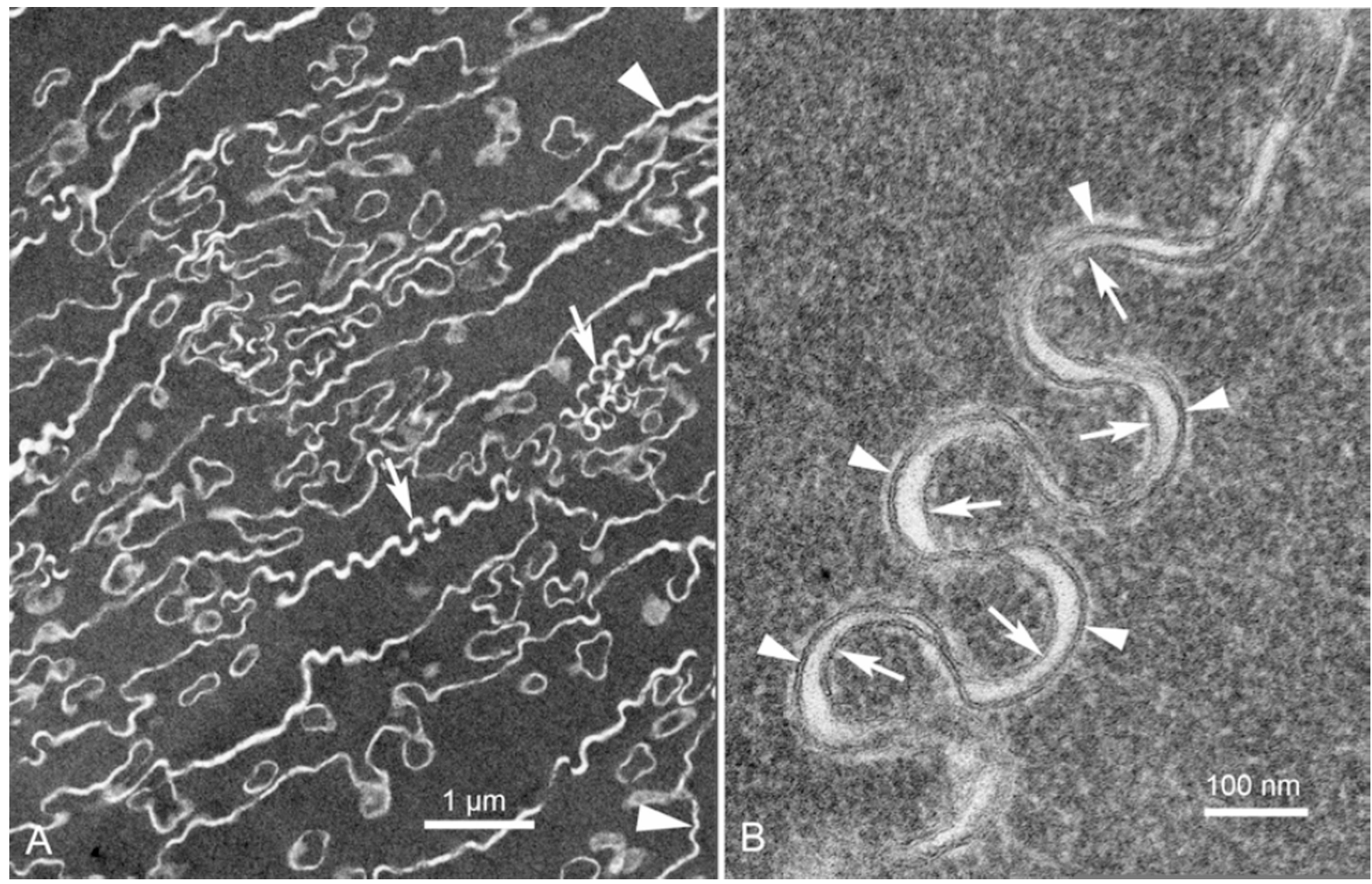

Figure 4. Undulating membranes of the TZ

A. Within about $50 \mu \mathrm{m}$ deeper than Fig. 2F, the membranes take on their characteristic undulating patterns, both low amplitude (arrowhead) and high amplitude (arrows). The cells are irregular in shape and are at the early stages of compaction with average cell thicknesses about $1 \mu \mathrm{m}$. Note the uniform dense staining of the cytoplasm. Also note that many circular profiles have irregular shapes because their membranes are also taking on the undulating morphology. B. At higher magnification the paired membranes of a region of high amplitude undulations can be seen individually. Based on previous studies, the segments that are convex toward the cytoplasm contain a high density of aquaporin0 (arrowheads) and the apposing concave segments are limited in protein or are pure bilayers (arrows). The membrane thickness is about $7 \mathrm{~nm}$. 

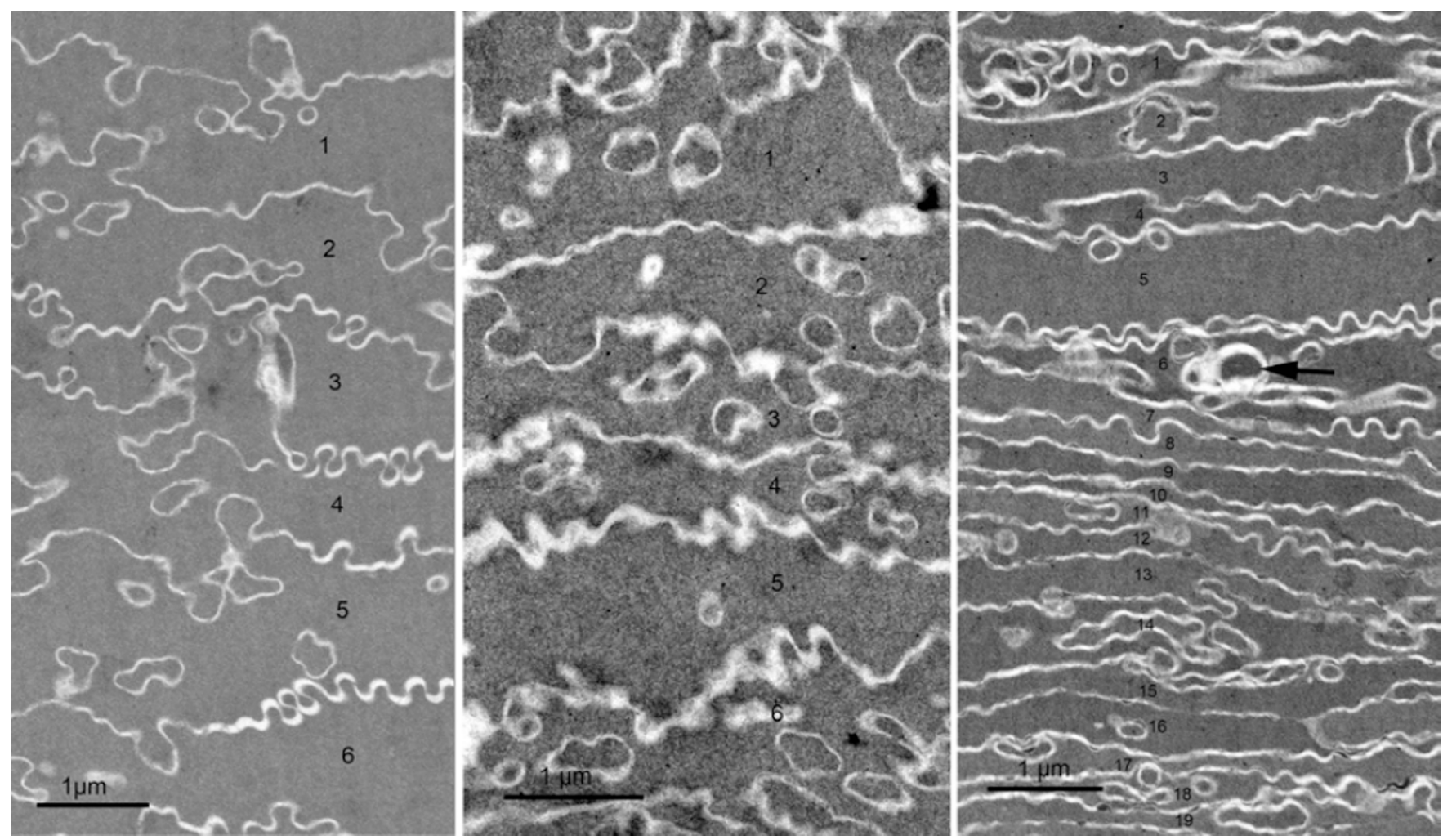

Figure 5. Fiber cell compaction as a function of lens age

TEM images were recorded at about $700 \mu \mathrm{m}$ from the capsule near the adult nucleus where all the cells have irregular shapes. A. Very little compaction was noted in the 22 y.o. donor lens. The six cells labeled 1-6 have an average thickness of approximately $1.1 \mu \mathrm{m}$ (compared to $2 \mu \mathrm{m}$ in the outer cortex in region FC in Fig. 1A). B. Somewhat greater compaction is seen in the 55 y.o. donor lens, here about $0.8 \mu \mathrm{m}$ average cell thickness for six cells 1-6. C. In the 92 y.o. donor lens, the cell width is variable with the average for this field of 19 cells (labeled 1-19) is about $0.4 \mu \mathrm{m}$. Note also that focal defect structures (arrow) are more common in the older lens. 